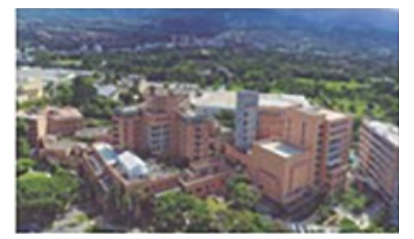

\title{
Caracterización de los Pacientes con Tumores Tímicos Manejados en una Institución de Alta Complejidad en Cali, Colombia, 2011 - 2019
}

Diego Scarpetta ${ }^{1}$, Eliana I. Morales ${ }^{2,1}$, Mauricio Velásquez ${ }^{3,1}$, Diana Martínez ${ }^{41}$, Luz F. Sua ${ }^{5,1}$ Liliana Fernández-Trujillo $0^{2,1}$

${ }^{1}$ Facultad de Ciencias de la Salud, Universidad Icesi. ${ }^{2}$ Depto de Medicina Interna, Neumología. ${ }^{3}$ Depto de Cirugía, Cirugía de Tórax. ${ }^{4} \mathrm{C}$. de Investigaciones Clínicas. ${ }^{5}$ Depto de Patología y Med. de Laboratorio, Fundación Valle del Lili. Cali, Colombia.

\section{Introducción}

Los tumores epiteliales tímicos son infrecuentes e incluyen: el carcinoma tímico, el timoma y los tumores neuroendocrinos. Representan el $0.2 \%$ al $1.5 \%$ de todas las neoplasias malignas.

El $75 \%$ son sintomáticos y predominan los síndromes paraneoplásicos (50\%) principalmente la miastenia gravis. El manejo de los tumores tímicos es complejo y requiere un equipo multidisciplinario.

\section{Objetivo}

Describir las características demográficas, clínicas, radiológicas, histopatológicas y quirúrgicas, y los desenlaces de los pacientes llevados a cirugía torácica por tumores tímicos en FVL.

\section{Material y métodos}

Estudio descriptivo retrospectivo observacional de una serie de casos.

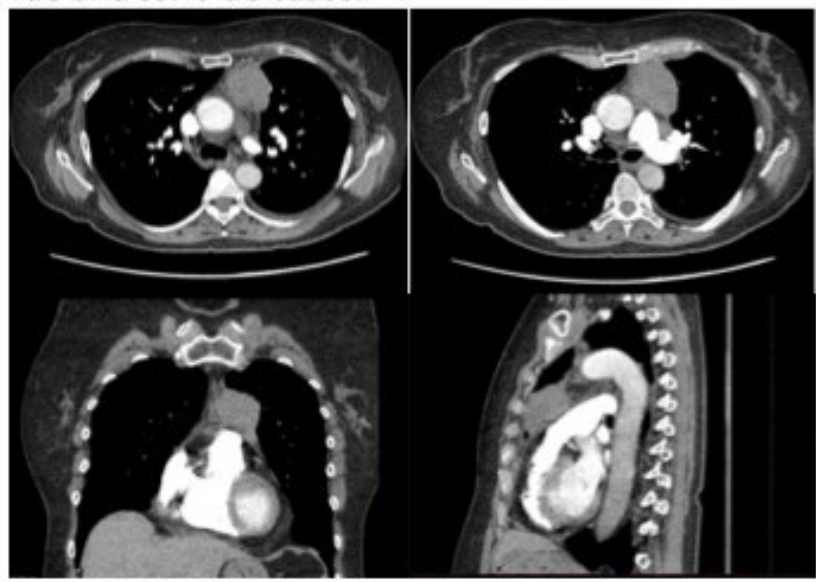

Carcinoma tímico en mujer de 72 años

\section{Resultados}

Se incluyeron 18 pacientes. $61,1 \%$ fueron hombres y $38,9 \%$ mujeres. Edad promedio 52,7 años. El $82,4 \%$ tuvieron síntomas: disnea $10(58,8 \%)$, tos 7 $(41,2 \%)$, dolor torácico $3(17,6 \%)$. Síndromes paraneoplásicos: miastenia gravis 2 (11,1\%), anemia aplásica $1(5,6 \%)$, síndrome de Cushing 1 $(5,6 \%)$. El $77,8 \%$ de las lesiones estaban en mediastino anterior; medida promedio $7,5 \mathrm{~cm}$; contornos lobulados $5(38,5 \%)$, irregulares 3 (23,1\%); densidad heterogénea $7(53,8 \%)$; calcificaciones $4(30,8 \%)$; derrame pleural $1(5,5 \%)$. Histopatología: timoma 13 (72,1\%), carcinoma 1 $(5,6 \%)$, tumor neuroendocrino $2(11,1 \%)$, timolipoma $1(5,6 \%)$, quiste timico $1(5,6 \%)$. Tratamiento: quirúrgico $16(89 \%)$, cirugía y quimioterapia $1(5,5 \%)$, cirugía, radioterapia y quimioterapia $1(5,5 \%)$; toracoscopia $12(66,6 \%)$, esternotomía $5(27,8 \%)$, toracotomía $1(5,6 \%)$. Desenlaces: estancia hospitalaria promedio 11,9 días; estancia en UCl 3,3 días; muertes intrahospitalarias $1(5,6 \%)$.

\section{Conclusiones}

Los tumores tímicos son infrecuentes. El pilar del tratamiento es quirúrgico. Ocurren alrededor de la $6^{\circ}$ década de la vida. Los síntomas son frecuentes pero inespecíficos y pueden debutar con síndromes paraneoplásicos.

\section{Bibliografía}

Scorsetti M, leo F, Trama A, D'Angelillo R, Serpico D, Macerelli M, et al. Thymoma and thymic carcinomas. Crit Rev Oncol Hematol. 2016;99:332-50. 